\title{
Development of agro-climatic grape yield model for Nashik region, Maharashtra, India
}

\author{
S.J. KADBHANE ${ }^{1}$ and V.L.MANEKAR ${ }^{2}$ \\ ${ }^{1}$ MVPS's KBT COE Nashik; ${ }^{2}$ SVNIT, Surat, Gujarat, India \\ Corresponding author: sharad_kadbhane@rediffmail.com
}

\begin{abstract}
Prediction of the crop yield is need of time according to the change in climate conditions. In the present study, the Agro-Climatic Grape Yield (ACGY) model has been developed with monthly climatic parameters using multi-regression analysis approach. The developed model was statistically tested for its predictive ability. The discrepancy ratio, the standard deviation of discrepancy ratio, mean percentage error and standard deviation of mean percentage error for the model was obtained as $1.03,0.19,0.03 \%$ and 0.19 , respectively. Sensitivity analysis was carried out for the developed ACGY model using the parametric sensitivity method. In order to know the future grape yield using ACGY model, climate scenarios were generated under Canadian Earth System Model (CanESM2) for three emissions representative concentration pathways as RCP2.6, RCP4.5, and RCP8.5. According to the analysis using ACGY model, increasing yield was observed in grape up to year 2050 as compared to current yield.
\end{abstract}

Keywords: Food security; grape yield; future climate projection; climate change

Grape (Vitis vinifera) is one of the important and main cash crops of the country. In the year 2019, India exported 2,16,582MT $\left(10^{3} \mathrm{~kg}\right)$ of grapes to European and Arabian countries, the cost of which was about 269.265 Million USD. The grape contributes $2 \%$ of total fruit exports, out of those $90 \%$ grapeswere exported only from the Nashik district (Saxena, 2014; APDEA, 2016). The weather effects and adoption approaches are notably becoming major areas of research on crop production (Hoogenboom, 2000; Yinhong et al., 2009). The globally changing climatic conditions are major threat which influences the food security of billions of people (Abbaspour, 1994; Droogers, 2004). An understanding of climate impact on the crop quality and quantity is essential for prediction of crop yield (Abraha and Savage, 2006).

Present crop models are location specific with limited variables. As far as Indian terrain is concern, there are very rare models found in the literature. The literature survey reveals, crop yield models are performing better on the local scale than global scale (Abraha and Savage 2006; Mohanty et al., 2017). Hence the current study was undertaken to develop Agro-Climatic Grape Yield (ACGY) model for Nashik district with reference to the current climate and it was tested with predicted future climate.For prediction of future climate the SDSM model was used (Taylor et al., 2012) and for this IPCC Fifth Assessment Report (AR5) was referred (Arora et $a l ., 2014)$. Future grape yield prediction was carried out separately, for three generated climate scenarios as RCP2.6, RCP4.5, and RCP8.5.

\section{MATERIALS AND METHODS}

In the development of ACGY model, the parameters from the climate domain were considered as temperature, precipitation, relative humidity, sunshine hour, and evapotranspiration. The climate data was collected from India Meteorological Department (IMD), Pune, India. The location of the study is $18^{\circ} 19^{\prime} 48$ to $20^{\circ} 31^{\prime} 48 \mathrm{~N}$ latitude and $73^{\circ} 09^{\prime} 36$ to $75^{\circ} 09^{\prime} 17 \mathrm{E}$ longitude at $565 \mathrm{~m}$ altitude.

\section{Phenological stages and climatic associations of grape plant}

The phenological cycle of the grape plant in the tropical and subtropical region has mainly six phenological stages i.e. bud breaking, vegetation growth, flowering, berry set, berry growth and ripening, and harvest (Baggiolini, 1952, Cancela et al., 2016). The grape plant in study area hastwo pruning cycles such as foundation pruning (April to September) and fruit pruning (October to March). In the study area the foundation pruning took place in first week of April and the fruit pruning in the first week of October. The phenological stages wise or particular month wise variation in the climate played a vital role in the grape production (Adsule, 2013).

\section{Statistical analysis for model development}

A sample correlation coefficient between the variables 
can be found using Pearson correlation coefficient (r). Essentially, $r$ is $-1 d$ " $r d$ " 1 showing negative and positive values of $r$ indicating linear correlation betweenthe variables. If $r$ is zero, then there is no linear correlation (Gupta, 1981). The significance parameter analysis was carried out using ttest and $p$-values. The t-statistics was calculated as the ratio of difference in the means and the standard error. The tstatistics can be calculated using the estimated pooled variance. Once the $t$-statistics value and degree of freedom are determined then $p$-value is determined using $t$-statistics table. Once hypotheses is proved then $p$-value $(<0.05)$ is an approximate value adopted as significant value (Gupta, 1981).

To develop ACGY model, the climatic parameter such as temperature and precipitation always shows the nonmonotonic effect on the crop yield. In the development of such models which need the involvement of multi-parameters (Gupta, 1981). In this study ACGY model was developed using multi-regression analysis. The parametric and component sensitivity method was used to found out independent parameters. The relative sensitivity value (RSV) of the input was computed using parametric sensitivity method. The higher value of relative sensitivity means grater the impact of the input parameter on output parameters.

\section{Forecasting of climate for future yield}

In this study, statistical downscaling model (SDSM) was used for prediction of future climate. Using SDSM it is possible to generate future climate scenarios (Wilby et al., 2002). As per IPCC $5^{\text {th }}$ Assessment Report (AR5) the Representative Concentration Pathways (RCPs) are new scenarios and it is the latest iteration of the scenario. The nomenclature of scenario was done according to radiative forcing target 2.6, 4.5, 6.0, and $8.5 \mathrm{Wm}^{-2}$ (Van et al., 2011). In this study mainly RCP $2.6,4.5$, and 8.5 were considered for forecasting the future climate.

\section{RESULTS AND DISCUSSION}

\section{Selection of model parameters}

From the literature survey it is revealed that grape yield (Y; MT ha ${ }^{-1}$ ) is mainly depend on climatological parameters (Lobell et al., 2007). To developed ACGY model climatological parameters (monthly) like average temperature $\left(\mathrm{T} ;{ }^{\circ} \mathrm{C}\right)$, cumulative precipitation $(\mathrm{P} ; \mathrm{mm})$, sunshine hours ( $\mathrm{SSH} ; \mathrm{hrs})$, relative humidity $(\mathrm{RH} ; \%)$ and evapotranspiration $\left(\mathrm{ET}_{\mathrm{o}} ; \mathrm{mm} /\right.$ day) are considered. In order to develop a relationship between the dependent and independent variables multi-regression analysis plays important role (Gupta, 1981). Functional grape yield is depending on climatic parametersand it can be represented as shown in Eq. (1);

$$
\mathrm{Y}=f\left(T, P, S_{h}, R_{h}, E T_{d}\right)
$$

After listing out the model parameters, correlation analysis was carried out to find whether any relation is exists between dependent and independent parameters.

\section{Correlation analysis for yield with climatic parameters}

To check the correlation of these climatic parameters, Pearson correlation analysis was carried out for the period of 1991-2016. The correlation coefficient ranges between +1 to -1 as shown in Table 1.

On the basis of results obtained, it is observed that if correlation coefficient is equal to or greater than \pm 0.3 then there is existence of relation between independent and dependent variables (Nikoliæ et al., 2012).

\section{Significance analysis using $t$-statistics and p-test}

The variables which are showing correlation as per table 1 are considered for significance testing. Once the tstatistics value and degree of freedom are determined then p-value can be calculated. According to Adekalu and Fapohunda (2006) if the p-value of the variable is less than 0.05 , then it is considered as significant and it is used for construction of the ACGY model. The t-statistics and $p$ value results are shown in Table 2.

It is observed that $p$-value is less than 0.05 for the monthly mean of minimum temperature in the January, April and November; precipitation in August and November whereas sum of monthly mean of evapotranspiration as shown in Table 2 . Hence, these parameters are statistically significant and are considered for development of ACGY model using multi-regression approach.

\section{Agro-Climatic grape yield model using multi-regression analysis}

Accordingly, coefficients for the model parameters were obtained from the multi-regression analysis and estimated model coefficients are summarized as shown in Table 3.

Hence using intercept and coefficient values (Table 3) the model wasdeveloped as shown Eq. (2).

$$
\begin{aligned}
& \mathrm{Y}=-44.67-1.60 \mathrm{~T}_{\mathrm{ja}}+1.33 \mathrm{~T}_{\mathrm{ap}}-0.49 \mathrm{~T}_{\mathrm{n}}-0.01 \mathrm{P}_{\mathrm{au}}-0.15 \mathrm{P}_{\mathrm{n}}+0.94 \\
& \mathrm{ET}_{\mathrm{o}} \ldots \ldots \ldots \ldots(2)
\end{aligned}
$$


Table 1: Correlation analysis between monthly climatic parameters and grape yield.

\begin{tabular}{llllllllllllll}
\hline $\begin{array}{l}\text { Months } \rightarrow \\
\text { Monthly } \downarrow\end{array}$ & Apr & May & Jun & Jul & Aug & Sep & Oct & Nov & Dec & Jan & Feb & Mar \\
\hline Avr. temp. & 0.12 & -0.07 & $\mathbf{0 . 3 0}$ & 0.18 & 0.20 & $\mathbf{0 . 3 0}$ & 0.12 & -0.13 & 0.13 & -0.01 & -0.05 & 0.09 \\
Max. temperature & -0.01 & $\mathbf{0 . 4 0}$ & -0.07 & $\mathbf{0 . 5 4}$ & -0.21 & 0.24 & 0.17 & 0.19 & 0.08 & -0.13 & $\mathbf{- 0 . 6 7}$ & -0.10 \\
Min. temperature & $\mathbf{0 . 3 5}$ & -0.24 & 0.00 & 0.09 & -0.02 & 0.09 & -0.28 & $\mathbf{- 0 . 5 5}$ & 0.02 & $\mathbf{- 0 . 5 4}$ & -0.28 & -0.13 \\
Precipitation & -0.09 & 0.04 & -0.20 & -0.11 & $\mathbf{- 0 . 3 0}$ & $\mathbf{0 . 3 2}$ & 0.12 & $\mathbf{- 0 . 7 9}$ & -0.22 & 0.14 & -0.05 & 0.15 \\
R. Humidity & -0.18 & -0.14 & 0.09 & -0.06 & $\mathbf{- 0 . 4 0}$ & $\mathbf{- 0 . 3 4}$ & 0.05 & $\mathbf{- 0 . 3 5}$ & -0.22 & 0.01 & 0.06 & -0.10 \\
Sunshine hours & $\mathbf{0 . 5 3}$ & -0.29 & 0.24 & 0.23 & 0.11 & -0.07 & $\mathbf{0 . 4 5}$ & $\mathbf{- 0 . 5 4}$ & 0.09 & $\mathbf{0 . 3 9}$ & -0.02 & 0.09 \\
ETo(mm/day) & $\mathbf{0 . 5 3}$ & $\mathbf{- 0 . 6 7}$ & -0.23 & 0.11 & -0.21 & -0.11 & -0.07 & $\mathbf{0 . 7 3}$ & $\mathbf{0 . 4 9}$ & 0.24 & 0.21 & $\mathbf{- 0 . 3 3}$ \\
\hline
\end{tabular}

Table 2: Results of t-stat and p-value of model parameters

\begin{tabular}{llllllll}
\hline Parameters & Month & t-stat & p-value & Parameters & Month & t-stat & p-value \\
\hline Avr. temp. & Jun & -0.03 & 0.976 & Relative Humidity & May & -0.608 & 0.586 \\
Max. temp. & Sep & 0.96 & 0.349 & & Jun & -0.468 & 0.672 \\
& Feb & -0.44 & 0.670 & & Aug & 0.468 & 0.672 \\
Min. temp. & Apr & 0.95 & 0.380 & Sunshine hour & Apr & -0.511 & 0.631 \\
& Nov & -1.56 & 0.170 & & May & -0.036 & 0.973 \\
& Jan & -3.35 & 0.000 & & Jun & 0.573 & 0.591 \\
Precipitation & Apr & 2.35 & 0.030 & & Aug & -0.252 & 0.811 \\
& Nov & -2.17 & 0.040 & & Nov & -1.730 & 0.144 \\
& Aug & -2.48 & 0.023 & & Dec & -0.095 & 0.928 \\
& Sep & 0.79 & 0.438 & ETo & Annual & 2.02 & 0.040
\end{tabular}

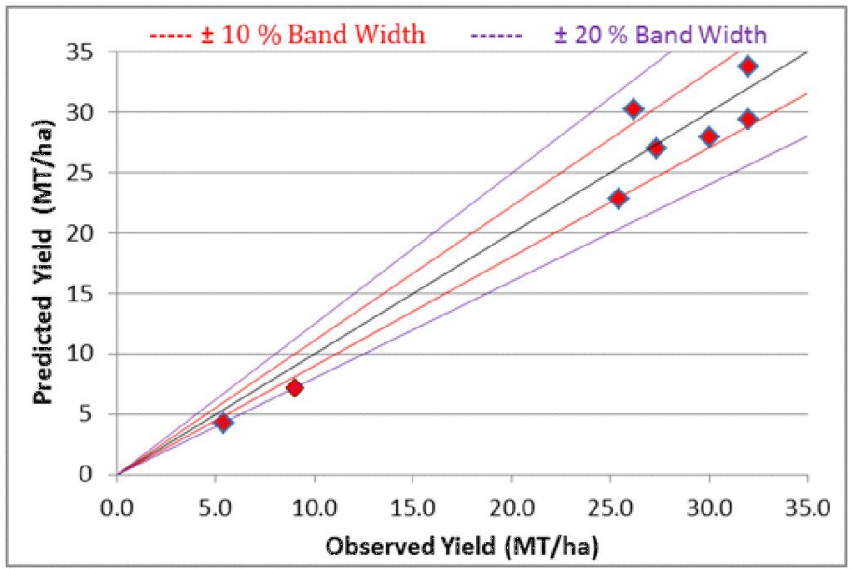

Fig. 1: Validation plot of the developed ACGY model Eq. $12(2009-2016)$

\section{The validation of ACGY model}

The recommendation for applicability of the developed ACGY model (Eq.2) is depends on its validation performance (Easterling et al., 1996). The independent variables for the period of 2009-2016 were used for the validation of developed model. A graph (Figure 1) is representing comparison between the observed and predicted grape yield. From the validation plot, it is observed that $62.5 \%$ of data points fall within $\pm 10 \%$ bandwidth and remaining $37.5 \%$ data point fall within $20 \%$ bandwidth. These values support the predictive capability of the developed model (Fernando et al. 2014).

\section{Sensitivity analysis of developed ACGY model}

Using parametric and component sensitivity method (Hamby, 1994) the relative sensitivity values were obtained for each parameter of the developed ACGY model.The relative sensitivity value (RSV) was calculated using componentslike $\mathrm{O}_{i}, \mathrm{P}_{i}$ and $\left(\delta \mathrm{P}_{i} / \delta \mathrm{O}_{i}\right)$. The value of mean output parameter $\left(\mathrm{O}_{i}\right)$ was 22.49. The input parameter, estimated coefficient $\left(\delta \mathrm{P}_{i} / \delta \mathrm{O}_{i}\right)$ and RSV are summarized in Table 4. 
Table 3: Coefficient for model parameters

\begin{tabular}{llllllll}
\hline & Intercept & Tmin. Jan. $\left(\mathrm{T}_{\mathrm{ia}}\right)$ & Tmin. Apr. $\left(\mathrm{T}_{\mathrm{ap}}\right)$ & Tmin. Nov. $\left(\mathrm{T}_{\mathrm{n}}\right)$ & Pre. Aug. $\left(\mathrm{P}_{\mathrm{au}}\right)$ & Pre. Nov. $\left(\mathrm{P}_{\mathrm{n}}\right)$ & ET $_{\mathrm{o}}$ \\
\hline Coefficients & -44.67 & -1.60 & 1.33 & -0.49 & -0.01 & -0.15 & 0.94 \\
\hline
\end{tabular}

Table 4: Results of sensitivity analysis

\begin{tabular}{lccc}
\hline Climatic parameters & Mean & Coefficient & RSV \\
\hline Monthly mean min. temperature in January $\left(\mathrm{T}_{\mathrm{ja}}\right)$ & 14.36 & -1.60 & -1.02 \\
Monthly mean min. temperature in April $\left(\mathrm{T}_{\mathrm{ap}}\right)$ & 23.19 & 1.33 & 1.37 \\
Monthly mean min. temperature in November $\left(\mathrm{T}_{\mathrm{n}}\right)$ & 17.83 & -0.49 & -0.39 \\
Monthly total precipitation in August $\left(\mathrm{P}_{\mathrm{au}}\right)$ & 181.28 & -0.01 & -0.08 \\
Monthly total precipitation in November $\left(\mathrm{P}_{\mathrm{n}}\right)$ & 18.07 & -0.15 & -0.12 \\
Sum of monthly mean Evapotranspiration $\left(\mathrm{ET}_{\mathrm{o}}\right)$ & 77.63 & 0.94 & 3.24 \\
\hline
\end{tabular}

Table 5: Statistical performance of the developed ACGY model (Eq. 12)

\begin{tabular}{ll}
\hline Statistical tests & $\begin{array}{l}\text { Developed ACGY } \\
\text { model (Eq. 12) }\end{array}$ \\
\hline Discrepancy ratio ( r) & 1.03 \\
Standard Deviation of r & 0.19 \\
Mean Percentage Error (MPE) & 0.03 \\
Standard Deviation of MPE & 0.19 \\
\hline
\end{tabular}

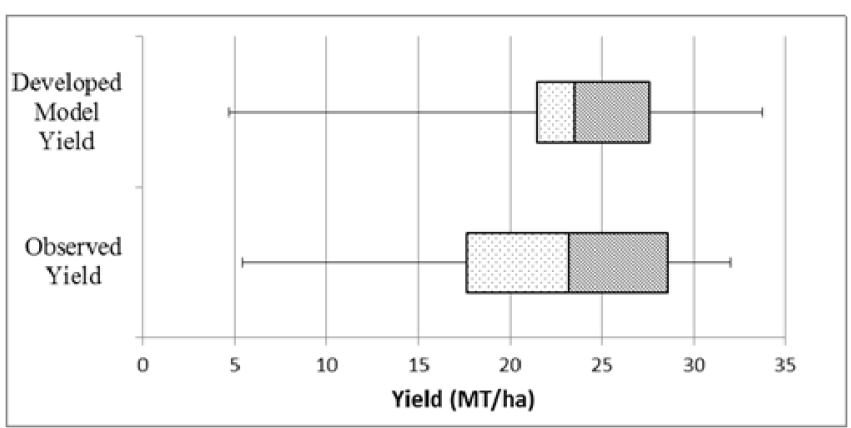

Fig. 2: Comparison between observed yield and model yield (Eq. 12) (1992-2016)

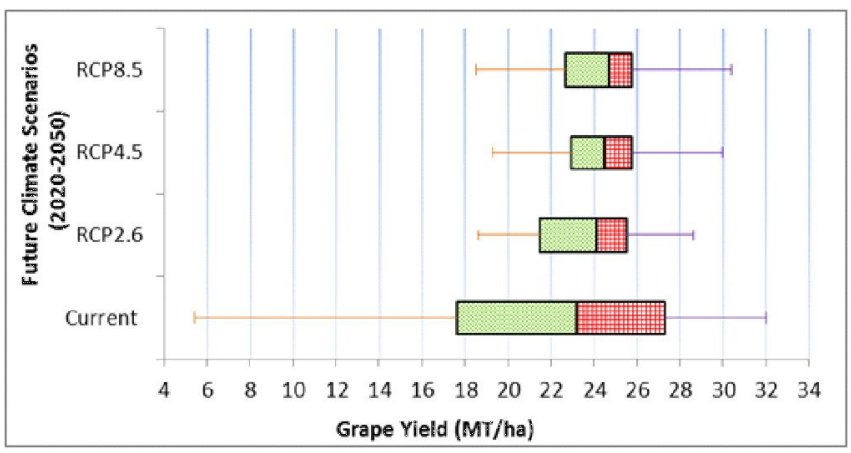

Fig. 3: Box plot of model response variability with reference to current and future
The higher value of relative sensitivity (RSV) indicating a higher sensitivity of that parameter. From the obtained results, evapotranspiration $\left(\mathrm{ET}_{\mathrm{o}}\right)$ is found to be most sensitive because of highest RSV 3.24. Whereas, monthly total precipitation in August $\left(\mathrm{P}_{\mathrm{au}}\right)$ is having lowest RSV -0.08, indicates less sensitivity. Most of agricultural crops are sensitive towards climatic parameters such as temperature and rainfall (Toure et al., 1995).

\section{The statistical performance of ACGY model}

The statistical fitness of the ACGY model was tested using statistical tests. The discrepancy ratio (r) is the ratio of simulated grape yield and observed grape yield. The ideal value of the discrepancy ratio is 1 . The mean percentage error (MPE) was calculated as the difference of simulated grape yield and observed grape yield divided by percentage observed crop yield (Bharadiy and Manekar, 2017). The obtained results of the statistical performance carried out for ACGY model is shown in Table 5. It reveals that the discrepancy ratio for ACGY model is 1.03 which is very close to ideal value as 1 (Bong et al., 2013). The results of model yield and actual yield are compared with consideration of the data during 1992 to 2016 (Fig. 2). Median of ACGY model is $23.5\left(\mathrm{MT} \mathrm{ha}^{-1}\right)$ and observed data is $23.2 \mathrm{MT} \mathrm{ha}^{-1}$. The upper quartile and lower quartile values are close to the median value of model yield as compare to observed yield. Hence, it is recommended that the developed ACGY model is found suitable to predict the grape yield for the study area (Mahmood et al., 2008).

\section{Prediction of future climate}

The future climate was derived using SDSM for the period of 2020-2050. The ACGY model was used to estimate grape yields for the current and future climate. The estimated 
Table 6: Statistical performance of the developed ACGY model (Eq.1) (2011-2016)

\begin{tabular}{|c|c|c|c|c|c|c|}
\hline \multirow[b]{2}{*}{ Statistical } & \multicolumn{2}{|c|}{ RCP2.6 } & \multicolumn{2}{|c|}{$\mathrm{RCP} 4.5$} & \multicolumn{2}{|c|}{ RCP8.5 } \\
\hline & Discrepancy & Mean \% & Discrepancy & Mean \% & Discrepancy & Mean \% \\
\hline Test & Ratio (r) & Error (MPE) & Ratio (r) & Error (MPE) & Ratio (r) & Error (MPE) \\
\hline mean & 1.08 & $8 \%$ & 1.16 & $16 \%$ & 1.22 & $22 \%$ \\
\hline SD & 0.58 & 0.58 & 0.65 & 0.65 & 0.80 & 0.80 \\
\hline
\end{tabular}

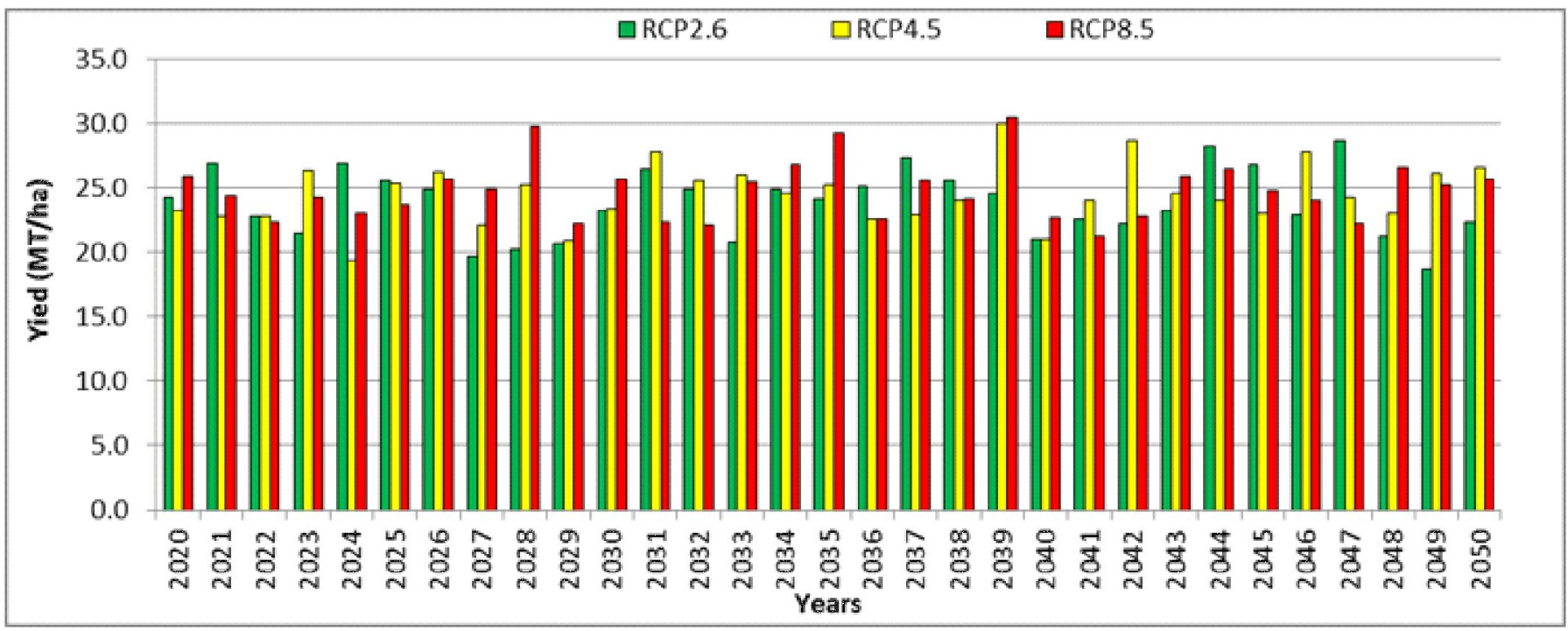

Fig. 4: Year-wise grape yield scenario under RCP2.6, 4.5 and 8.5 using developed ACGY model (2020-2050)

crop yield is then compared in box and whisker plot to understand the model response variability with the current and future climate (Van et al., 2011) as shown in Fig. 3. AS per the analysis, future climate median yields are observed as 24.1 $\mathrm{MT} \mathrm{ha}^{-1}$ under RCP 2.6, 24.52 $\mathrm{MT} \mathrm{ha}^{-1}$ under RCP4.5 and $24.72 \mathrm{MT} \mathrm{ha}^{-1}$ under RCP8.5 scenarios. It is observed that in the future grape yield increase as compared to the current climate.

\section{Year wise future grape yield scenario}

The crop yield scenario was generated by considering the existing field management practices. Using ACGY model and projected climate scenario under RCP2.6, 4.5, and 8.5, grape yield scenario was generated(Van et al., 2011). The obtained grape yield scenario under three RCPs during the year 2017 to 2050 is shown in Fig. 4. Under RCP2.6 the lowest crop yields of $18.63 \mathrm{MT} \mathrm{ha}^{-1}$ is observed in the year 2049. This is due to the fact that precipitation occurred in the month of November was $72 \mathrm{~mm}$ which is the highest precipitation as predicted. The maximum crop yield is found in the year 2047 as $28.64 \mathrm{MT} \mathrm{ha}^{-1}$ due to the fact that August precipitation is observed as $91.01 \mathrm{~mm}$ and November precipitation is $34.53 \mathrm{~mm}$ which is near to the lowest values of precipitation. The highest crop yield is found in the year 2039 (30.40 $\mathrm{MT} \mathrm{ha}^{-1}$ ) with November precipitation $6.44 \mathrm{~mm}$ and August precipitation $92.97 \mathrm{~mm}$. According to Lobell et al., ( 2007) yield climate relationships can provide a foundation for forecasting crop production within a yearand for projecting the impact of future climate changes.

\section{Statistical performance of developed model forclimate scenarios as RCP2.6, 4.5 and 8.5}

The statistical fitness of the ACGY model over the projected data for the duration of 2011-16 is checked using statistical tests. Obtained results of all tests are shown in the Table 6. It is observed that ACGY model is performing most satisfactorily under RCP2.6 scenario. From the obtained results of statistical performance, it is observed that the ACGY model is performing satisfactorily for the projected climate data obtained under different climate scenarios as RCP2.6, 4.5 and 8.5 (Lobell et al., 2006).

\section{CONCLUSION}

The discrepancy ratio, the standard deviation of discrepancy ratio, mean percentage error and standard deviation of mean percentage error for the ACGY model is 
obtained as $1.03,0.19,0.03 \%$ and 0.19 , respectively. From the obtained results of sensitivity analysis, it is found that sum of monthly mean evapotranspiration, the monthly mean minimum temperature in April and precipitation in August parameters found to be more sensitive. According to future grape yield scenario grape crop showing increasing yield in the future i.e. up to 2050 as compared to current yield. From the obtained results of statistical performance of the ACGYmodel, it is observed that model is performing better for future yield predictions under three RCP scenarios.

\section{ACKNOWLEDGEMENT}

The authors would like to thank IMD, Pune for provided climatic data and Dr. K.T. Patil for proof reading the article and for constructive comments.

\section{REFERENCES}

Abbaspour, K.C. (1994). Bayesian risk methodology for crop insurance decisions. Agri. Forest Meteorol., 71: 297314.

Abraha, M.G. and Savage, M.J. (2006). Potential impacts of climate change on the grain yield of maize for the midlands of KwaZulu-Natal, South Africa. Agric. Ecosyst. Environ., 115: 150-60.

Adekalu, K.O. andFapohunda, H.O. (2006). ANumerical Model to predict Crop Yield from Soil Water Deûcit. Biosyst. Engineer, 94(3): 359-372.

Adsule, P.G. (2013). Good agriculture practices for production of quality table grapes. Report of a national research center for grapes, Manjari, Pune., 1-83.

APDEA. (2016). Agriculture production development and Economics authority India. Export of Agro. Food Products Report., 20-32.

Arora, V.K., Boer, G.J. and Christian, J.R. (2009). The Terrestrial photosynthesis down-regulation on 20th-century carbon budget simulation with CCCma Earth System Model. J. Climate, 22(22): 6066-6088.

Baggiolini, M. (1952). Les stadesrepères dans le développement annuel de la vigne el leur utilisation 477 practique. Rev. Romande Agric.Vitic. Arboric., 8:4-6.

Bharadiya, N. and Manekar, V. (2015). Development of agroclimaticwheat yield model for Surat district, India using dimensional analysis. J. Agrometeorol., 17(2): 223226.

Bong, C. H., Lau, T. L. and Ghani, A.Ab. (2013). Verification of equations for incipient motion studiesfor a rigid rectangular channel. Water Sci. Technol., 67(2): 395403.

Cancela, J. J., Trigo-Córdoba, E., Martínez, E. M., Rey, B. J., Bouzas-Cid, Y. and Fandiño, M. and Mirás-Avalos, J.M. (2016). Effects of climate variability on irrigation scheduling in white varieties of Vitisvinifera (L.) of NW Spain. Agric. Water Manage., 170: 99-109.

Droogers, P. (2004). Adaptation to climate change to enhance food security and preserve environmental quality: an example for southern Sri Lanka. Agric. Water Manage., 66:15-33.

Easterling, W.E., Xiafen, C., Cynthia, H., James, R. and Brandle, H.Z., (1996). Improving the validation of modelsimulated crop yield response to climate change: an application to the EPIC model. Climate Res., 6: 263273.

FAO. (2016). FAO-OIV FOCUS 2016. Table and dried grape, 32-33.

Fernando, S., Hugo, S. and Paula, S. (2014). Degree-day model of table grape (Vitisvinifera L.) Phenology In Mediterranean Temperate Climates. Int. J. Sci. Environ. Technol., 3(1): 10-22.

Gupta, S.G. (1981). Fundamental of statistics. Himalaya publishing house, 7(27): 1-31.

Hamby, D.M. (1994). A review of techniques for parameter sensitivity analysis of environmental models. Environ. Monitor. Assess., 32: 135-154.

Hoogenboom, G. (2000). Contribution of agro-meteorology to the simulation of crop production and its applications. Agric. Forest Meteorol., 103: 137-57.

Lobell, D., Cahill, K. and Field, B. (2007). Prioritizing climate change adaptationneeds for food security in 2030 . Science, 319: 607-10.

Lobell, D., Field, C., Cahill, K. and Bonfils, C. (2006). Impacts of Future Climate Change on California Perennial Crop Yields: Model Projections with Climate and Crop Uncertainties. Agric. Forest Meteorol., 1-19.

Mahmood, R., Mark, M., David, R.L. and Mark, L.M. (2008). The CERES-Rice Model-Based Estimates of Potential Monsoon Season Rainfed Rice Productivity in Bangladesh. The Professional Geographer, 55(2): 259 273. 
Mohanty, M., Sinha, N.K., McDermid, S.P., Chaudhary, R.S., Sammi Reddy, K., Hati, K.M., Somasundaram, J., Lenka, S., Patidar, R.K., Prabhakar, M., Cherukumalli, S.R. and Patra, A.K. (2017). Climate change impacts vis-a-vis productivity of soybean in vertisol of Madhya Pradesh. J. Agrometeorol., 19(01): 10-17.

Nikoliæ, D., Muresan, R.C., Feng, W. and Singer, W. (2012). Scaled correlation analysis: a better way to compute a cross-correlogram. European J. Neurosci., 1-21.

Saxena, M. (2014). Handbook on horticulture statistics 2014. Government of India Ministry of Agriculture Department of Agriculture and Cooperation New Delhi., 25-26.

Srinivastav, A.K. (2015). Agriculture statistics system in India.NSSO (FOD), 1-2

Taylor, K.E., Stouffer, R.J. and Meehl, G.A. (2012). An overview of CMIP5 and the experiment design. Bull. American Meteorol. Soc., 93(4): 485-498.
Toure, A., Major, D.J. and Lindwall, C.W. (1995). Sensitivity of four wheat simulation models to climate change. Canadian J. Plant Sci., 75: 69-74.

Van Vuuren, D.P., Edmonds, J.A., Kainumaa, M., Riahi, K. and Weyant, J. (2011). A special issue on the RCPs. Climate Change, 109(1): 1-4.

Wilby, R.L., Dawson, C.W. and Barrow, E.M. (2002). SDSMa decision support tool for the assessment of regional climate change impacts. Environ. Modelling Software., 17: $147-159$

Yinhong, K., Shahbaz, K. and Xiaoyi, M.(2009).Climate change impacts on crop yield, crop water productivity, and food security - A review. Progress Natural Sci., 19: 16651674. 